careful review of cardiac catheterization assists in determining this risk. Preemptive right axillary artery and/ or femoral vessel access or exposure is performed selectively in at-risk patients. Further details of the operative approach are described in Appendix $\mathrm{E} 4$ of the manuscript.

Eric E. Roselli, MD

Department of Thoracic and Cardiovascular Surgery

Cleveland Clinic

Cleveland, Ohio doi:10.1016/j.jtcvs.2008.03.021

\section{Redon drains and underwater seal: The better of two worlds? To the Editor:}

We read with interest the recent article of Gwozdziewicz, Nĕmec, and Steriovsky ${ }^{1}$ describing a technique of chest drainage after cardiac surgery with Redon drains (B. Braun Melsungen AG, Melsungen, Germany)

Five Redon drains are placed in an elaborate fashion into the pericardial space and further drains are added if the pleura are opened and require drainage. The drains are attached to a reservoir under suction of -800 mbar $\left(816 \mathrm{~cm} \mathrm{H}_{2} \mathrm{O}\right)$.

On one hand, we fully agree with the advantages of using Redon drains and add the following to those already cited by the authors: (1) the ease with which these drains are removed, being less painful and requiring minimal or no analgesia, and (2) the fact that only one suture is needed to fix them and no closure is necessary after removal as compared with standard chest tubes. On the other hand, we use only two Redon drains, which correspond to drains 2 and 5 according to Gwozdziewicz's scheme, with number 5 being placed more toward the right ventricle. Occasionally, a third mediastinal Redon drain is added if the patient is at a particular risk for bleeding complications. It is often placed in regard to the culprit site, for example, the left atrium in mitral valve surgery. In case of pleural space drainage, one Redon drain is placed into each pleura as necessary. Moreover, in one of our patients, suction necrosis developed on a venous graft that was in direct contact with one of these Redon drains. This was attributed to the high suction pressure attained by connecting these drains to the reservoir as described in the article. We, therefore, connect the Redon drains to a sterile underwater valve seal system,

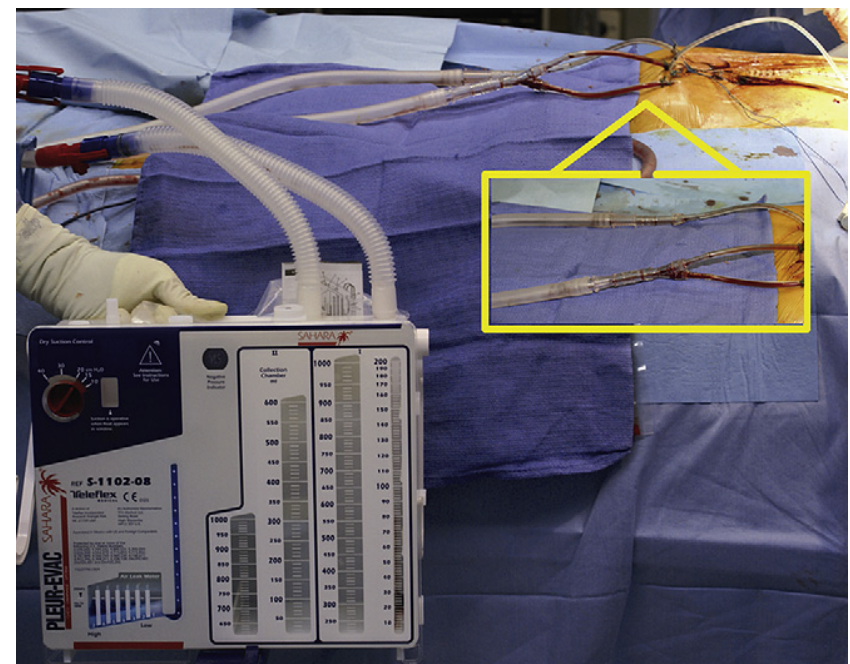

Figure 1. Redon drains attached to an underwater seal system. The suction pressure is regulated at $-20 \mathrm{~cm} \mathrm{H}_{2} \mathrm{O}$. Inset shows connection of drains to system tubing.

Pleur-evac chest drainage unit or Pleurevac Sahara chest drainage dual tube (Teleflex Inc, Research Triangle Park, NC) when the pleura are intact or open, respectively (Figure 1). These systems are completely silent and produce no bubbling sound. They evidently require an external source of suction but control the suction pressure of the Redon drains to around $-20 \mathrm{~cm} \mathrm{H}_{2} \mathrm{O}$, minimizing considerably the risk of a suction lesion on the heart or coronary grafts. We have not encountered such a lesion in our experience with more than 2000 patients in whom this system was applied.

We congratulate the authors on their work and look forward to their feedback on the points we raised.

$$
\begin{array}{r}
\text { Nawwar Al-Attar, FRCS, FETCS, PhD } \\
\text { Richard Raffoul, } M D \\
\text { Patrick Nataf, } M D \\
\text { Bichat Hospital } \\
\text { Paris, France }
\end{array}
$$

\section{Reference}

1. Gwozdziewicz M, Němec P, Steriovsky A. An alternative approach for chest drainage after cardiac surgery: Redon drains. J Thorac Cardiovasc Surg. 2008;135:216-7.

doi:10.1016/j.jtcvs.2008.02.050

\section{Reply to the Editor:}

I greatly appreciate the comments of our French colleagues on our article describing an alternative approach to chest drainage us- ing Redon drains. The main concern they raised was that the high suction used in our system could cause suction lesions on the heart or coronary grafts. They have experienced one case of bypass necrosis resulting from the high suction, but no such complication occurred in our cohort of 4297 patients. I have occasionally observed suction lesions on the heart or even the grafts during reoperations for bleeding when removing a drain that was in direct contact with them, but such lesions always appeared harmless and never led to any problems. In my opinion, the case of bypass necrosis described by Al-Attar, Raffoul, and Nataf was due to the coincidence of direct contact of the drain with a deficient wall of the venous graft.

Their interesting but certainly isolated case report of graft necrosis does not convince me to abandon our technique. I have also seen some isolated complications when using standard $32 \mathrm{~F}$ chest tubes over the years, including graft thrombosis caused by tube compression or even fatal hemorrhagic shock caused by bleeding from the intercostal vessel in the posterior chest wall that was eroded by the chest tube. However, there is no surgical procedure that carries no risks.

When using our technique, care should be taken to avoid direct contact of the Redon drains with the grafts, and this can be achieved by positioning the drains as described in our article: on the bottom of the opened pericardial cavity and leaning against the pericardium rather than lying on the surface of the heart. The only situation in which the drains 
may be in close contact with the myocardium is when the pericardium is closed, which we routinely avoid when any grafts are put on the coronary arteries.

It should also be remembered that the applied suction is $-816 \mathrm{~cm} \mathrm{H}_{2} \mathrm{O}$ only at the beginning of the drainage, with this decreasing as the reservoir fills with blood.

I should like to clarify that I have a different experience regarding the pain caused by the removal of Redon drains. Even though I remove them after disconnecting them from the reservoir (some surgeons do not disconnect them), the maneuver is no less painful than removing $32 \mathrm{~F}$ chest tubes.

It is possible to use fewer drains in the pericardial cavity, and some of the surgeons at my institution prefer to insert only two or three of them. However, in my opinion the previously proposed scheme of four drains covering all regions around the heart is optimal.

I have recently changed the position of the left pleural drain, inserting it through the back wall of the pericardium rather than through its lateral wall, as described in our article. This is done so as to avoid the possibility of phrenic nerve injury. It is mandatory during this maneuver not only to lift the pericardium but also to deflate the lungs, especially during off-pump surgery, to avoid cautery lung injury.

The optimal negative pressure for our drainage is still unclear, but $-20 \mathrm{~cm} \mathrm{H}_{2} \mathrm{O}$ seems too low for drains with an inner diameter of $2 \mathrm{~mm}$. However, the main drawback of the French drainage system is the substantial additional cost caused by the use of a Pleurevac unit (Teleflex Inc, Research Triangle Park, NC). The cost difference between using five Redon drains with reservoirs (as we do) and using three $32 \mathrm{~F}$ chest tubes plus a Atrium Oasis 3600 (Atrium Medical Corp., NH, USA) reservoir is around $\$ 140$ (US) per patient.

In summary, I would encourage our French colleagues and other surgeons to reconsider their drainage systems in favor of the one presented in our article.

Marek Gwozdziewicz, MD, PhD University Hospital Olomouc Olomouc, Czech Republic doi:10.1016/j.jtcvs.2008.03.024

\section{Robotic cardiac surgery: Give it more time!}

To the Editor:

We read with great interest a recent editorial by Dr Francis Robicsek regarding his per- ception that robotic cardiac surgery has essentially been a failure. ${ }^{1}$ The data presented are excellent and support the conclusion that robotic cardiac surgery has not to date been as widely adopted as some predicted. His unrelenting assault on robotic cardiac surgery does reflect the view of many cardiac surgeons ${ }^{2}$ and must be seriously considered. But is he correct in dismissing such a oncepromising technology so soon?

We too have had concerns about robotic cardiac surgery: that it has been used by many as a marketing tool, that a thoracotomy is more painful than a sternotomy, that the operations can be done more easily with endoscopic approaches, and that operative time is increased. However, this all changed for me when I had the privilege of being exposed to the work of 2 incredibly talented master surgeons, Dr Doug Murphy from Atlanta and Dr Leland Siwek from Spokane, Washington. These surgeons have nearly perfected the technique of totally endoscopic mitral valve repair ${ }^{3}$ to the point at which if I needed that operation today, I would have one of them do it. Others have made major advances in revascularization procedures., What these and several other courageous surgeons have done is built world-class teams around existing technology. The reason that the rest of us have struggled with these cases is hard to face: we have not been able to muster the same level of local support and team building that is necessary to make the existing technology work. Many of us would have little difficulty doing these procedures if integrated into their programs.

Robotic cardiac surgery will eventually prevail, just not on as rapid a timeline as some might want. The da Vinci robot (Intuitive Surgical, Inc, Sunnyvale, Calif) was only approved for cardiac surgery in 2002. Are we to declare failure after only 6 years? The new system is far improved over the original, and the development of a robotic atrial retractor and improved visualization has made the procedures dramatically easier. We do need additional technologic improvements, such as automated suturing devices, tactile feedback, simpler anastomotic devices, an assistant surgeon console, and better training. Most of the technology needed to perfect robotic cardiac surgery already exists; it only needs to be integrated. We must also recognize that every cardiac surgery unit should not do robotic surgery. Instead, highly specialized centers with dedicated teams and supportive environments are already emerging. Surgeons uncomfortable with mitral repair or off-pump coronary surgery through a sternotomy and those without major institutional support should stay away from the robot.

On a deeper level, we must recognize that innovation must become the mantra of this specialty for it to survive. One of the reasons for the declining interest in the specialty is a perception that we are not innovating and therefore doomed to extinction. Endovascular innovation is being recognized as something we must embrace. I would add other minimally invasive approaches, such as robotics, to this effort. Rather than throwing in the towel, we should work to fix the current technical limitations of robotic cardiac surgery just as our predecessors tackled challenges of similar difficulty in years past. We have for too long lived off of their accomplishments.

Ironically, the first cardiac surgery I saw was in 1989 in the summer before medical school. The surgeon was Dr Francis Robicsek. He was larger than life and commanded unquestioned respect from everyone in the hospital and clearly deserved it. This is where my first interest in cardiac surgery as a profession began. He and his partners spoke of an exciting time in cardiac surgery at which all sorts of new innovations were occurring. I was hooked. Dr Robicsek, it is time to revive that spirit, not kill it.

$$
\begin{array}{r}
\text { T. Sloane Guy, MD, } M B A^{a, b} \\
\text { Elaine Tseng, } M D^{a, b} \\
\text { Department of Surgery } \\
\text { University of California } \\
\text { San Francisco Veterans Administration } \\
\text { Medical }{ }^{b} \text { Center } \\
\text { San Francisco, Calif }
\end{array}
$$

\section{References}

1. Robicsek F. Robotic cardiac surgery: time told! J Thorac Cardiovasc Surg. 2008;135: 243-6.

2. Damiano RJ Jr. Robotics in cardiac surgery: the Emperor's new clothes. J Thorac Cardiovasc Surg. 2007;134:559-61.

3. Murphy DA, Miller JS, Langford DA, Snyder AB. Endoscopic robotic mitral valve surgery. J Thorac Cardiovasc Surg. 2006; 132:776-81.

4. Argenziano M, Katz M, Bonatti J, Srivastava S, Murphy D, Poirier R, et al. Results of the prospective multicenter trial of robotically assisted totally endoscopic coronary artery bypass grafting. Ann Thorac Surg. 2006;81:1666-75. 